\title{
José Ramón Fernández Ojea e a aplicación da música popular nas escolas
}

\author{
Xosé FERNÁNDEZ FERNÁNDEZ \\ Facultade de Ciencias da Educación da Universidade de Vigo
}

O documento que se ofrece a continuación, titulado "El canto regional en las escuelas”, é obra do polígrafo ourensán José Ramón Fernández Ojea (Ramón era o seu primeiro apelido e Ojea aparece tamén como Oxea e Ogea en distintas publicacións que nós respectamos), quizais máis coñecido co pseudónimo respectuoso de Ben-Cho-Shey ${ }^{1}$. Foi un mestre e inspector de ensino primario comprometido coa transformación educativa de Galicia seguindo os principios innovadores e renovadores da pedagoxía contemporánea e demandando a promulgación de normas lexislativas que autorizasen o bilingüismo nas nosas escolas. Levaba o galeguismo e a música nas veas, ata o punto de que nada máis escoitar unha gaita se puña a bailar.

\section{Formación e actividade profesional dun home profundamente galeguista}

O noso home nace en Ourense o 5 de abril de 1896 nunha familia de cinco fillos, moi poucos anos despois dunha serie de personaxes relevantes no ámbito do galeguismo, tal como se recolle no Rexistro Civil da década de 1880 e cos que necesariamente mantivo algunha relación máis ou menos estreita compartindo ideas, espazos, traballos e tempo de lecer. Entre eses persoeiros, por citar uns poucos, cabe mencionar a Antón Villar Ponte (1881-1936), creador do periodismo galego e das Irmandades da Fala; os profesores e amigos ourensáns Antón Losada Diéguez e Vicente Risco, nados en 1884; Florentino López Cuevillas, Alfonso Daniel Rodríguez Castelao e Johán Vicente Viqueira, en 1886; e xa, por último, Ramón Otero Pedrayo, en 1888. Mesmo, con Risco e Otero, en 1927 foi compañeiro dunha peregrinaxe ao antiquísimo santuario de santo André de Teixido, camiñada que lles permitiu auscultaren unha parte enxebre do territorio galego que vai dende Ourense ás terras de Cariño, nas que Ben-Cho-Shey permaneceu algún tempo breve de mestre e das que recolleu determinados aspectos relacionados co folclore e que chegou a publicar en La Voz de Ortigueira².

\footnotetext{
${ }^{1}$ José Ramón y Fernández Ojea, "El canto regional en las escuelas", Bibilioteca Deputación Provincial de Ourense, Arquivo BCS, Sección Pedagoxía-Ensino, Caixa 66.

${ }^{2}$ Ramón Otero Pedrayo, Pelerinaxes I (A Coruña: Nós, 1929). Obra publicada na imprenta Nós cando estaba na rúa Real, $30-1^{\circ}$ da Coruña. Nesta longa viaxe, durmindo nas pousadas da aldea, pasaron por Viana, Monterroso, Palas de Rei, Lugo, Vilalba, As Pontes de García Rodríguez e Ortigueira. Conta
} 
Tampouco debemos esquecernos do influxo familiar. José Ramón era fillo de Pío Ramón, un coñecido profesor da cidade das Burgas que impartía clases como auxiliar de letras na Escola Normal de Ourense, organismo en que tamén adoitaba ocupar o cargo de secretario durante a tempada estival, compartindo esta actividade coa dirección do colexio privado San José de Calasanz, en que cursou os primeiros estudos o cativo José Ramón. Ademais, Pío Ramón era membro das Irmandades da Fala e foi un dos asinantes das actas da Asemblea Nacionalista de Lugo, en 1918, ano en que o seu fillo se incorpora precisamente a filas como radiotelegrafista oficial -título conseguido con grande éxito nos exames correspondentes-; chegou a exercer o cargo de cabo primeiramente e sarxento despois e tivo como un dos destinos a cidade de Melilla. De por parte, don Pío estaba ao tanto dos principios pedagóxicos da ILE e mesmo tivo certa relación con algún dos seus líderes. Existe unha carta remitida por Manuel Bartolomé Cossío aos mestres e mestras de Ourense, datada en Betanzos o 16 de agosto de 1912 con motivo de asistir a unha asemblea informativa onde se tratasen os problemas do ensino que afectaban de forma particular a esta provincia, á que finalmente non puido acudir e que se celebrou no Paraninfo do Instituto o 25 de agosto de $1912^{3}$. Desa xuntanza, da que se tirou unha serie de conclusións que afectaban á escola ourensá, Pío Ramón Oxea era o principal impulsor xunto co mestre da Normal Basilio Carmona, Luís Soto Menor e José María González, ademais de ser o director do Boletín del Magisterio (1906-1912), medio que informaba das principais novidades pedagóxicas e lexislativas ao corpo do Maxisterio cando a provincia estaba tan necesitada de instrución e cultura, de mestres e escolas que se reflectían nuns índices de analfabetismo e falta de asistencia escolar tremendamente preocupantes. Cargos desempeñados aos que cabe engadir o ser o fundador da Asociación Provincial do Maxisterio de Ourense e portavoz do Partido Galeguista na deputación provincial entre 1934 e 1936.

Mais, centrándonos xa na formación académica e pedagóxica de Ben Cho Shey, home consecuente que mantivo un compromiso perenne co galeguismo dende os seus anos mozos ata a súa morte, digamos que cursou o bacharelato no Instituto Provincial de Ourense entre 1906 e 1912 e en 1915 aprobou a reválida de mestre de Primeira Ensinanza con premio extraordinario. O amor por Galicia

cun interesante prólogo a cargo do profesor da Escola de Maxisterio de Ourense, Vicente Risco, que cita a escola Satyâgraha Ashram de Gandhi na India, a Rousseau, Huysmans e de como destas camiñadas se pode tirar proveito científico e fomentar o amor á terra. Foi reproducida en formato facsimilar por Ediciós do Castro en 1993.

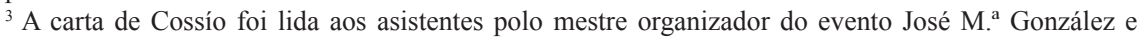
nela reclamábanse para a provincia ourensá, entre outras cousas, "Escuelas, muchas escuelas; porque si, a veces las pocas que hoy hay están vacías es poque el padre, con razón, las haya inútiles, el niño ingratas, ambos difíciles" e "muchos y buenos maestros". Véxase "Los maestros gallegos. El mitin celebrado en el Paraninfo del Instituto", Boletín del Magisterio, Ourense, no. 254 (5-9-2012): 1-2. Tamén se fai referencia a esta carta en Antón Costa Rico, A reforma da educación (1906-1936). X. V. Viqueira e a historia da Psicopedagoxía en Galicia (A Coruña: Ediciós do Castro, 1996), 34 e 35. 
axiña emerxe no personaxe sendo mozo. En 1918 xa comeza a publicar n 'O Tío Marcos d'a Portela, para deseguido continuar no diario agrario La Zarpa, Diario de Vigo, entre moitos outros onde fala dalgunhas cuestións educativas como a ensinanza da historia, a ximnasia nas escolas ou terza opinando dende El Pueblo Gallego sobre "A fala galega", ante a necesidade de consensuar unhas normas de uso deste idioma que facilitarían a súa aplicación en ámbitos tan precisados como era á súa consideración no ensino.

En 1925, tras causar baixa no Batallón de Radiotelegrafía de Campaña por corresponderlle o licenciamento e obter en 1923 o título de mestre nacional na Escola Superior de Maxisterio de Madrid con sobresaliente e premio extraordinario, supera a oposición de Maxisterio cun primeiro destino na escola de nenos de Cariño, onde substitúe a outro importante membro das Irmandades da Fala, o mestre e poeta Vitoriano Taibo que neses anos debatía cuestións sobre as normas ortográficas que debían rexer na "uniformación" do idioma galego no espazo habilitado para tal fin, "Tribúa Aberta. A fala galega", do xornal El Pueblo Gallego ${ }^{4}$. Diario vigués que continuaba, así, a andaina emprendida nos primeiros debates insinuados no voceiro nacionalista $A$ Nosa Terra en 1919 sobre os criterios que cumpría seguir na unificación ortográfica, terreo en que tamén o mestre ourensán Ben-Cho-Shey deu as súas opinións. Nesta estadía no cabo do Ortegal recompila os seus primeiros traballos sobre a etnografía. Ao ano seguinte pasa á escola unitaria de Santa Marta de Moreiras (O Pereiro de Aguiar), destino que lle permite coñecer dúas realidades distintas, como diría el, a mariña e a Galicia rural do interior, sobre as que realizou dúas interesantes memorias que presentou no acceso á Inspección Educativa seguindo as bases requiridas conforme o goberno da II $^{\mathrm{a}}$ República $^{5}$.

Entre 1927-1930 cursa estudos na Sección de Xordomudos e Cegos na Escola Superior de Maxisterio, onde chega a facer algún traballo sobre a educación especial de cegos e a realizar como exercicio práctico a aplicación do método de Binet e Simon. Esta sección funcionaba xunto coas de Ciencias, Letras e Labores e durante o ano común compartían as materias de Pedagoxía, Fisioloxía, Paidoloxía, Pedagoxía de Anormais, Psicoloxía e Debuxo. Nesta institución madrileña impartían clases profesores relevantes debidamente seleccionados como Luis de Hoyos Sáinz, José Rogelio Sánchez, Rufino Blanco Sánchez, Domingo Barnés, Jacobo Orellana, Rafaela R. Placer e María Luisa Navarro, entre outros. Como alumno puido visitar o "Grupo Escolar Cervantes" que xunto co "Príncipe de Asturias" eran modelo de organización de ensinanza graduada e contaban tamén cunha sección de Educación Especial. Neles había unha ampla liberdade de horarios e programas. Cursando estes estudos, en 1928, ano en que

\footnotetext{
${ }^{4}$ Nestes debates participaron, entre outros, Leandro Carré, Victoriano Taibo, Johán Carballeira, Vicente Risco, Fermín Bouza Brey, Xaquín Lorenzo, X. Bal e Gay, J. de Loira e Evaristo Correa Calderón. Desevolvéronse con distinta intensidade especialmente entre os anos 1925 e 1929.

${ }^{5}$ Carmen Benso Calvo e Xosé Fernández Fernández, “José Ramón Fernández-Ojea, mestre. Memoria do seu paso por dúas escolas galegas", Sarmiento, no. 6 (2006): 277-287.
} 
ingresa tamén no Seminario de Estudos Galegos, é bolseiro polas deputacións de Ourense e Pontevedra para visitar as escolas máis destacadas de Francia e Bélxica, países europeos que lle permiten observar as experiencias levadas a cabo en establecementos de ensinanza primaria, de nenos anormais mentais e físicos, institucións para xordomudos e para cegos. Experiencias do visto, oído e vivido que, tal como relata na memoria realizada ao respecto, o impresionaron ao mesmo tempo que lle causaron certa tristeza ao ver o adianto pedagóxico destes países onde se ensinaba con métodos activos inspirados en María Montessori e Decroly, en comparación co atraso en que se achaba a aprendizaxe en Galicia ${ }^{6}$.

Xa na II ${ }^{\mathrm{a}}$ República, en 1934, aproba a oposición de Inspector de Ensino Primario e obtén destino en Lugo, cidade onde reside no n. ${ }^{\circ} 18$ da rúa Santiago. De aquí sería trasladado a Cáceres en 1937 e previamente suspendido de emprego e soldo durante tres meses, por ser presidente do Partido Galeguista daquela cidade dende 1936, cos cargos de "ser galeguista" e "participar en actos políticos de izquierda". Cargo imputado de "ser galeguista" que nunca negou, ni tan sequera no prego de descargos. Alí reside no número 15 da rúa de Moret e agora tócalle a el informar expedientes depurativos feitos a mestres. Responsabilidade que realiza con cautela, procurando non prexudicalos xamais na súa carreira profesional. Tamén informa sobre os problemas educativos desta provincia: "El estado de la enseñanza en esta zona de mi cargo es normal, en cuanto se refiere al comportamiento de los Sres. maestros, que se esfuerzan en el cumplimiento de su deber pese a las dificultades con que empiezan en el desarrollo de su labor y que son los siguientes: falta de asistencia de los niños, falta de colaboración de los Ayuntamientos y la escasez de material escolar"7. Como inspector foi sempre un gran defensor dos dereitos dos mestres e mestras porque, como el apuntaba en certa ocasión, "entre inspectores y maestros más que la distancia de superior a inferior hay la cordialidad del amigo y del compañero".

Deseguido, en virtude da Orde ministerial do 26 de setembro de 1951 (BOE do 25 de outubro) pola que resolve o concurso de traslados de inspectores, adxudícaselle con carácter definitivo unha praza na provincia de Toledo, onde se xubila en 1967. Exercendo nesta provincia, en 1956, por primeira vez, estivo á fronte do posto da Editorial Galaxia na Feira Nacional do Libro, en Madrid, cidade onde residía no andar primeiro do número 72 da rúa Martín de los Heros e mantiña contactos co Centro Galego, localizado no terceiro andar do número 14 da rúa Carretas. Durante esta estadía súa na capital de España foi un soporte importante para o galeguismo da emigración e grupos literarios como Brais Pinto. Nesta cidade morre o 2 de maio de 1988 e os seus restos foron trasladados días

${ }^{6} \mathrm{O}$ proxecto e a memoria sobre as experiencias vividas na ensinanza de anormais durante súa estadía de estudos en Francia e a Bélxica gárdase inédita na Biblioteca da Deputación Provincial de Ourense, Arquivo BCS, Sección Pedagoxía-Ensino, Caixa 66.

${ }^{7}$ Biblioteca da Deputación Provincial de Ourense, Arquivo BCS, Sección Ensino-Inspección de Ensino, Caixa 62. 
despois ao cemiterio de San Francisco de Ourense. Así mesmo, como un dos máis grandes amantes e investigadores da festa dos Maios, todos os anos viña dende Madrid para visitar esta festa en Pontevedra, Marín, Poio, Vilagarcía e Caldas o día primeiro de maio, e o día 3 en Ourense ${ }^{8}$. Algunhas desas imaxes e experiencias de varios anos formaron parte dunha conferencia pronunciada en galego na Coruña, no outono de 1971, dentro dun ciclo temático sobre Galicia. ${ }^{9}$

\section{Consideracións relativas ao traballo sobre o canto rexional nas escolas}

O traballo titulado "El canto regional en las escuelas" está escrito en vinte e tres cuartillas mecanografadas e custodiadas na Biblioteca da Deputación Provincial de Ourense, organismo que conserva o seu arquivo particular xunto aos de Alberto Vilanova, Álvaro de las Casas, Benito Fernández Alonso, Manuel Albendea Gómez de Aranda, Eduardo Blanco Amor, Alonso Montero e as irmás Pura e Dora Vázquez, entre algúns outros. Pese a amar tanto o seu autor á lingua galega, está redactado en castelán polas circunstancias políticas do momento de sobra coñecidas, agás as cantigas que se transcriben segundo foron recollidas da boca da xente e o seu falar procedente da oralidade, cando non existía ningún tipo de fixación na escrita. O traballo ten o mérito de ser presentado como un relatorio ao solemne Congreso Pedagóxico Rexional celebrado na cidade da Coruña en outubro 1926, coincidindo coa implantación da Festa do Mestre, que se establecera mediante o Real decreto do 26 de marzo de 1926 e que fixaba a súa celebración na data do 1 de outubro de cada ano. Neste caso os actos clausuraríanse o día 12 de outubro, Día da Festa da Raza. Fomentar congresos rexionais estaba dentro dos plans da política do goberno primorriverista e no caso concreto deste realizado en Galicia daba continuidade a outro organizado sobre a economía galega o ano anterior en Lugo e do que aínda se tiraran algunhas conclusións verbo da situación do ensino na nosa terra en temas espiñentos como a necesaria creación de escolas e o fomento da asistencia escolar.

Malia o matiz rexional que se lle pretendía dar, houbo algunhas comunicacións en que se abordaban os problemas privativos da escola galega que non se puideron tratar. Entre elas estaba o emprego do canto rexional nas escolas presentada polo mestre Ben-Cho-Shey, corresponsal de La Zarpa, outra sobre a adaptación da escola galega ao seu medio natural e social e unha terceira en que se abordaba a necesidade de ensinar en galego mediante un plan pedagóxico establecido por Vicente Risco, profesor e daquela director accidental da Escola Normal de Ourense, ademais de ser destacado teórico do nacionalismo galego ${ }^{10}$. Relatorios seguramente beneficiosos por canto estaban pensados fundamentalmente para o

\footnotetext{
${ }^{8}$ José Paz Rodríguez, “Os 'maios’ festa do amor”, La Región, 3/5/2006, 21.

${ }^{9}$ Xosé Ramón e Fernándex Oxea, "Ciclo 'Galicia'. Vellas tradiciós da nosa Galicia: os maios” (A Coruña: Club de Dirigentes de Empresa-Cámara Oficial de Comercio, Industria e Navegación, 29 de outono de 1971).

${ }^{10}$ Xosé Fernández Fernández, Vicente Risco. Mestre de mestres (Ourense: Deputación Provincial-Fundación Vicente Risco, 1914), 157-189.
} 
seu desenvolvemento na escola rural á que acudía a inmensa maioría dos nenos e nenas de Galicia e que eran monolingües polas limitacións do seu hábitat. Non se puideron ler por impedimento das autoridades adictas ao réxime do xeneral Primo de Rivera, supoñemos - as razón exactas non se citan- que debido a considerar que podían atentar contra os ideais políticos da época sobre a familia, a relixión, a patria, o idioma e a unidade nacional.

Nin o seu aparentemente inofensivo título, "El canto regional", nin estar o texto escrito en castelán por un autor que tanto amaba a lingua galega -deixou escrito que na súa lápida o epitafio figurase nesta lingua- foron suficientes para darlle o visto e prace por parte da comisión responsable do evento. Ben seguro que foi a súa aplicación "en las escuelas" o motivo fundamental de rexeitamento nun contexto político centralizador e controlador, e especialmente sensible cos ideais que se transmiten a través do ensino. Pois noutros eidos culturais se viñan tolerando estudos de campo con este tipo de materiais realizados no terreo do folclore ou etnográfico, entre os que tamén figuraba o estudo do cantigueiro popular en que predominan procesos psicolóxicos de ledicia, mágoa, frustración, dor de ausencia, celos, sentimento lírico, melancolía, saudade, tenrura, sarcasmo, con fondas raizames na etnia galega e que tan ben chegou a analizar outro docente ourensán, Xoaquín Lorenzo Fernández. Actitude permisiva talmente reflectida no labor que estaba realizando un grupo de intelectuais dende a plataforma do Seminario de Estudos Galegos ou dende a propia revista Nós, que seguiron funcionado baixo a atenta mirada da censura, por tirar dous exemplos próximos no espazo e no tempo ao personaxe tratado.

Sen dúbida, para o autor das Burgas o canto que máis penetra na alma é o canto rexional, por iso esta forma é a que máis deben cultivar os mestres e as mestras. Aínda que se centra en Galicia por razón obvias, a súa proposta podería ser extensible perfectamente ao conxunto do resto de España onde abundan rexións ou comunidades autónomas con este tipo de cantos. Vexamos, a modo de entrecolleita: Cataluña posúe as súas "sardanas", Valencia o seu baile "chaquera", Aragón a súa "jota", os alacantinos os seus "cantos de trilla", os andaluces o seu "cante jondo", Castela e León os seus cantos de berce, os vascos o seu baile popular tradicional expresado nas oitavas do "zortziko" e Galicia a súa muiñeira xunto coa conmovedora melodía dos alalás da que o canto popular provoca unha profunda sensación.

Probablemente o meirande valor que co emprego da música popular se transmita aos nenos e nenas das escolas de Galicia sexa o galeguismo que se poida inculcar con ela, especialmente se as formas proceden dunha selección feita con esmero por mestres comprometidos coa cultura e saberes da súa terra. Valores presentes de forma parecida no plano pedagóxico para a galeguización da escola de Risco, defensor de introducir no ensino aspectos da cultura oral e tradicional que o alumnado xa traía consigo e que el traballou nas súas clases como mestre de mestres por tres razóns fundamentais: a primeira consiste en que 
motivaban a aprendizaxe ao partir do próximo, do coñecido, correspondéndose co recomendado polas correntes pedagóxicas modernas; a segunda, de acordo tamén con eses movementos pedagóxicos, porque permiten introducir novas materias e metodoloxías no ensino rachando con aquelas fixadas dende a época da Restauración; e a terceira, con eles aprendíase ao mesmo tempo a valorar e respectar as cousas do país, a exaltación da nacionalidade e a procura do auténtico e do propio. É dicir, a facer patria. Por iso Risco cando fala da galeguización da escola considera a necesidade de tratar tamén a música popular (xunto cos traballos manuais, a ximnasia...) e remite para ese asunto a este proxecto do seu colega Ben-Cho-Shey presentado ao citado congreso coruñés, por considerar que era o docente que mellor podía tratar este tema ${ }^{11}$.

Fiando co anterior, os motivos que segundo o propio Risco impiden tratar estes contidos relacionados co galeguismo van referidos á falta de liberdade de cátedra no maxisterio oficial, polo que os escolantes do Estado non podían, aínda que tivesen vontade, introducir novidades neste sentido. Polo tanto, onde se podía unicamente facer cousas era nas escolas particulares, iniciativas que tamén afectaban aos materiais curriculares, de aí que as Irmandades da Fala da Coruña tivesen interese en publicar libriños elementais de xeografía e historia de Galicia, gramática, vocabulario castelán-galego etc. Pois a liberdade de cátedra encontrou de inmediato as limitacións do Réxime. Unha real orde do 13 de outubro de 1925 definía como a Ditadura entendía a liberdade dos profesores, recollendo que os docentes que exercían na ensinanza pública eran invitados a "dar ejemplo paladino de virtudes cívicas dentro y fuera de las aulas". Aos reitores indicábaselles que vixiaran coidadosamente "acerca de las doctrinas antisociales o contra la unidad de la patria".

Despois do citado congreso nada se soubo da continuidade deste proxecto de Ben-Cho-Shey. Feito que corrobora o dito de que na escola pública pouco ou nada se podía facer en cuestión de galeguismo por mor do control estatal ao que estaban sometidos os profesionais do ensino. Talvez cando Galicia fose autónoma a cousa podería cambiar ${ }^{12}$. Mentres todo quedaba en man de docentes desinteresados e dalgunha iniciativa particular coma foi o caso da "Escolas do Insiño Galego" que funcionou durante seis anos (1924-1930) na Coruña, cunha asistencia moi limitada e con clases impartidas polo esforzado irmandiño Ánxel Casal, benfeitor da revista Nós e que chegaría a ser alcalde de Santiago durante algún breve tempo, tristemente asasinado como tantas outras persoas comprometidas con Galicia nada máis producirse a chegada da guerra que anticipaba tempos convulsos.

Sexa como for, o congreso resultou ser un gran momento perdido para poder tratar problemas de transcendencia para o Maxisterio e dar a coñecer estas iniciativas novas e alentadoras entre os numerosos mestres e autoridades presentes

\footnotetext{
${ }^{11}$ Ibídem , 206-2014.

${ }^{12}$ Vicente Risco, “A Galeguización da Escola”, A Fouce, no. 29 (1/3/1931).
} 
de dentro e fóra de Galicia. A súa relevancia púxose de manifesto no feito de ser seguido durante unha semana polos xornais de distintas localidades e ideoloxías coas súas respectivas queixas por parte dalgúns deles: A Nosa Terra, El Noroeste, La Región, El Ideal Gallego, La Voz de Galicia, La Zarpa, e El Pueblo Gallego, entre outros.

Non obstante, Ben-Cho-Shey dinos, para o interese da pedagoxía, canto de proveito ten o emprego dos cantos populares que cada rexión ten de seu e como estes se poden utilizar na aprendizaxe. Pódese dicir que foi un dos poucos galeguistas que se mergullou no tema con certo rigor. Viqueira puxera énfase tamén neste tema, mais a súa morte prematura, acontecida en 1924, cando contaba con 38 anos de idade, privouno seguramente de seguir profundando neste asunto coma en tantos outros.

Por outra banda, en consonancia con cantar en galego está tamén falar en galego. Neste ámbito Ben-Cho-Shey considerou sempre que os nenos deben educarse, na primeira ensinanza polo menos, no seu idioma natural, tal como recomendaban os pedagogos e congresos internacionais. A ese respecto, sinala nun artigo publicado en 1957 na revista Galicia do Centro Galego de Bos Aires de que "es elemental que las enseñanzas de los idiomas deben hacerse a través de la lengua materna y, si los niños gallegos no saben el castellano, lo primero que hay que hacer es enseñárselo, pero siempre valiéndose de los conocimientos lingüísticos del niño. De no hacerlo así éste adquirirá la técnica de la lectura de un modo mecánico y llegará a leer el castellano sin enterarse de lo que lee"13. Como talmente así acontecía cos nenos e nenas das aldeas que segundo moitos mestres da época lían perfectamente o castelán, sen saber ou comprender nada do que lían. Ademais, para pensar en galego non hai máis camiño que falar e escribir en galego. Todo o demais será pensar no idioma que cada quen prefira usar ${ }^{14}$. Situación que tamén lles afectaba aos estudantes que cursaban bacharelato, que tiñan un vocabulario castelán limitadísimo, cheo de barbarismos e unha sintaxe enxebremente galega. Mesmo o profesor Filgueira Valverde chegou a notar que os seus alumnos pontevedreses, de cuarto e quinto, non se decataban da maior parte das explicacións porque non entendían o castelán ${ }^{15}$.

Para pór en práctica o dito e axudar nesta tarefa pedagóxica a nenos e escolantes, o propio Ben-Cho-Shey comprometeuse confeccionando un Catón galego, que tiña preparado en 1936, pero que sería publicado moi posteriormente por Edicións do Castro, en 1969, con cuberta de Luís Seoane. Manual escolar de primeiras letras que dedica a todos os nenos e escolantes galegos, pois, como el di na súa presentación, aínda que somos un país bilingüe, en Galicia o galego

\footnotetext{
${ }^{13}$ José Ramón Fernández Oxea, "Enseñanzas. Los niños gallegos”, Galicia, revista del Centro Gallego de Buenos Aires, no. 494 (marzo-abril de 1957): 5.

${ }^{14}$ José Ramón Fernández, "Pensar en galego", La Noche, 22/11/1948.

${ }^{15}$ Ben-Cho-Shey, "O lingoaxe nas escolas", A Nosa Terra (20-12-1935): 3.
} 
Prá mór parte de nós é a nosa lingoa materna. E como tódolos pedagogos de tódolos tempos aconsellan o emprego da lingua materna no ensino dos nenos, para que iste postulado pedagóxico se podia cumprir e levar a termo en Galicia compuxemos iste método de lectura pensando nos cativos e nos escolantes galegos ou que exercen o seu maxisterio na nosa terra, para que de agora en diante dispoñan dun instrumento que lles sirva a iste propósito.

Era o segundo destas características tras o Método de lectura da mestra Josefa Iglesias Vilarelle, editado polas Publicacións Escolares do Seminario de Estudos Galegos en 1932, unha das poucas mulleres pertencentes ao galeguismo de preguerra que tivo certa relevancia na actividade política pública do nacionalismo. Escrito enteiramente en galego, o manual do ourensán principia co ensino das vogais e consoantes, pasando logo a frases con significado coñecido para os rapaces. Fiel á música popular, inclúe "Cantos de Aninovo", "Cantos de Reises" (recollido do volume Terra de Melide), cantigas de Curros Enríquez, Rosalía de Castro, panxoliñas etc. Recolle unha moi coñecida nana popular que reproducimos a continuación:

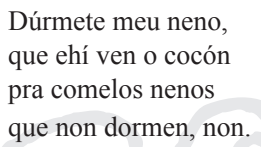

Mesmamente, entre a documentación persoal de Ben-Cho-Shey, que se garda na Biblioteca da Deputación de Ourense, consérvanse precisamente varios sobres con panxoliñas de poesía popular, ademais doutras poesías escritas en galego durante o franquismo de autores pouco coñecidos: M. Pereiro Muíño, Manoel Alexandro, Xoel Ferral, M. ${ }^{a}$ Luz Rey Cascallar e Carballo Calero, entre outros documentos de poemarios e cantigas redactadas tamén polo propio autor. A isto súmase a existencia de numerosas tarxetas de felicitacións de Nadal cheas de enxebrismo que Ben-Cho-Shey coleccionaba escrupulosamente, con personaxes infantís de protagonistas, en moitas das cales os nenos e as nenas aparecen vestidos con traxe rexional e tocando algún instrumento de música popular do noso país.

Aténdonos xa ao que é o contido do traballo en si, "El canto regional en las escuelas", o autor comeza xustificando o porqué do que está a planear. A razón non é outra que partir do novo concepto da educación introducido na pedagoxía contemporánea que, como xa comentamos, deixaba atrás os desfasados principios educativos tradicionais baseados no enciclopedismo e no memorismo, afastados da vida activa dos nenos e nenas e centrados na repetición dos libros de texto. A escola que existía nas últimas décadas do século XIX, tanto a pública como a privada, era herdeira dunha aprendizaxe baseada nos principios de autoridade e na obediencia cega á palabra do mestre, mentres os alumnos permanecían en silencio, agás que se lles solicitase a súa participación. O material usado viña confeccionado dende fóra da institución escolar, que estaba ao servizo dunha instrución rodeada dunha disciplina moi ríxida que correspondía ao coñecido dito de que "a letra con sangue entra". 
Fronte a esta maneira de ensinar xorden os partidarios dunha escola activa que planean un modelo didáctico e educativo que pouco tiña que ver co sinalado. Aparece unha nova concepción do mestre, que pasa a desempeñar novos roles, como o de ser un coordinador de actividades, un orientador e motivador, mentres que os nenos se converten agora en figuras clave ao redor dos que xira todo o proceso do ensino-aprendizaxe. A este novo modelo súmanse os cambios producidos nos libros de texto, que non existen como tales, senón que dan pautas de traballo e de actividade, e, cunha programación previa, profesorado e alumnado van construíndo conxuntamente os contidos a partir dos intereses e motivacións dos propios rapaces. Esta nova visión da aprendizaxe vén propiciada por unha longa lista de institucións e movementos educativos renovadores que se opuxeron na súa época á educación vixente. Nesa listaxe aparecen autores tan destacados como Rabelais, Dewey, Montaigne, Reddie, Herbart, Comenio, Locke, Rousseau, Pestalozzi, Decroly, Froebel, Tolstoi, Montessori, Dalton, Winnetka, Claparède, Ferrière, Washburne, Cousinet e Kilpatrick, por citar algúns dos máis representativos. Paralelamente irán emerxendo correntes innovadoras e renovadoras cos nomes de Escola Moderna, do Traballo, Activa ou Nova, que contaban con experiencias noutros países europeos e americanos dende finais do século XIX e primeiros anos do vinte. España e Galicia non permaneceron tampouco alleas aos seus predicamentos.

Numerosos mestres de primeiro ensino participaron na reforma da escola española, especialmente aqueles que mantiveron unha relación destacada coa Institución Libre de Ensinanza e o movemento da Escola Nova, ambas coincidentes na maioría dos seus principios. Precisamente dentro do ideario da Escola Nova estaba basearse nos feitos e nas experiencias, recorrer á actividade e espontaneidade do neno, apostar pola introdución de materias como a educación artística e moral, a música, a educación física, os traballos manuais, o excursionismo e a estimulación de actividades libres, así como polas viaxes a pé debidamente programadas para realizar traballos de campo. Como sinal destes contactos, o propio Ben-Cho-Shey, noutro manuscrito, que se conserva tamén no seu arquivo da biblioteca provincial ourensá, contempla a necesidade de tratar os traballos manuais nas escolas ${ }^{16}$. Feito para o que recorre pedagoxicamente á obra Gargantúa, de Rabelais, na que se simultanean exercicios corporais co traballo manual; a Comenio, que fala do gusto que senten os nenos por traballar en barro e madeira; a Locke, que concede unha grande importancia ao traballo agrícola e á madeira; a Rousseau, Montaigne, Basedow, Salzman e Pestalozzi. Sobre todo cita a Froebel, por considerar que foi a partir del cando os traballos manuais colleron importancia na ensinanza moderna. Modalidade en que se distinguiron especialmente as nacións do norte de Europa: Finlandia foi o primeiro país que as introduciu na súa lei de Instrución pública, Suecia contaba coas escolas de Nääs en Gotemburgo e o Instituto de Palmgen

${ }^{16}$ José Ramón Fernández y Ojea, "Trabajos manuales”, Bibilioteca Deputación Provincial de Ourense, Arquivo BCS, Caixa 66, Cartafol ensino-notas manuscritas. 
en Estocolmo, Noruega con escolas ambulantes de Slöjol, que realizaban estas actividades cos nenos a domicilio. No resto de Europa menciónase a célebre escola Ripatransone en Italia e países como Dinamarca, Alemaña, Holanda, Suíza, Inglaterra e Bélxica, onde os mestres tiñan que saber traballar en madeira, en arame e modelar para poder conseguir o título.

Resulta evidente, pois, que o movemento da Escola Nova e os contactos coa ILE tiveron repercusión no pensamento pedagóxico do galeguismo, introducindo conceptos reformadores que fomentaban unha educación activa e intuitiva, á vez que significativa, ao facer constantemente uso do medio próximo como un recurso útil e necesario, o que fomentaba a motivación e o desenvolvemento do proceso de ensino-aprendizaxe ${ }^{17}$. Ao respecto, permítasenos lembrar que cando Risco elaborou, precisamente en 1921, o único plano realizado en Galicia para a galeguización, innovación e reforma do ensino, o "Plan pedagóxico pra galeguización d'as escolas", propuña o emprego da música popular, seguindo o programa de Ben-Cho-Shey e tendo en conta os principios aquí referidos. Ese proxecto obedecía á petición dos persoeiros das Irmandades da Fala, tras as pretensións en materia escolar da III Asemblea Nacionalista Galega reunida na cidade olívica; e, antes de dalo a coñecer, foi revisado polo ilustre pedagogo Ignacio Ares de Parga, un home formado na ILE, que concibía o ensino como un instrumento emancipador e creador de benestar social. Profesor que durante a súa estadía madrileña tivera unha grande amizade con Giner de los Ríos, relación que se mantivo despois dende Bos Aires de forma epistolar cando estaba realizando neste país da diáspora un importantísimo labor educativo e cultural e de onde, en 1921, fora enviado a Galicia como delegado para o acto de inauguración da Biblioteca América da Universidade de Santiago. Esta viaxe aprovéitaa tamén para observar o funcionamento da importante escola "Union Hispano-Americana de Valle Miñor", da que existen xa numerosos estudos e para contactar con membros da mocidade galeguista de Ourense, a súa cidade natal.

En consonancia coas correntes pedagóxicas comentadas, Ben-Cho-Shey xustifica a proposta do seu traballo en que "los diferentes tipos de escuela moderna -la escuela renovada, la escuela activa, la escuela del trabajo, etc.- han venido a revolucionar la enseñanza con sus procedimientos novísimos haciendo de la escuela un lugar grato en donde conviven amistosamente maestros y discípulos unidos en la redentora labor educativa que tiende a reivindicar para el niño sus derechos a la libertad de movimiento, a la libertad del trabajo, a la alegría, al juego y también al canto y a la danza". ${ }^{18}$ E segue recalcando que dentro desas formas diversas máis ou menos expresivas do mundo da arte "es el canto la que mejor ha logrado aclimatarse en las escuelas, mucho mejor que el dibujo, que el modelado y

\footnotetext{
${ }^{17}$ Anxo Serafín Porto Ucha, La Institución Libre de Enseñanza en Galicia (Sada: Ediciós do Castro, 1986), 99-100.

${ }^{18}$ José Ramón y Fernández Ogea, "El canto regional en las escuelas”, 1.
} 
que los trabajos manuales. Aún en aquellas escuelas en que más penoso se les hace el apartarse de la secular rutina se oye a veces cantar a los chicos".

No tocante a autores individuais, recorre de maneira especial ás achegas do mestre Benedito, e tamén ao que está a acontecer en certos países europeos localizados nas vangardas pedagóxicas, como era o caso de Alemaña -poderíase citar tamén a Italia ou Suíza-, país de grandes músicos e que tiña a música e o canto incluídos nos seus programas escolares, que prevían a execución por nenos e mestres de "delicadísimos lieders en los que a la fantasía de los mejores poetas se ha unido el genio de los grandes maestros de la música". Se isto se facía noutros países, por que non se había facer en Galicia? Pois o lieder, como unha obra musical sinxela e chea de poesía, cun carácter marcadamente popular, contaba con presenza tamén na nosa terra. En palabras recollidas do programa que anexamos do propio mestre Ben-Cho-Shey indícase que

nosotros tenemos nuestro tesoro de música popular capaz de competir con su enorme valía con el de todos los pueblos europeos. Nuestras canciones populares que llenan con sus mágicas armonías todo el brumoso ambiente de la tierra gallega, están saturadas del aroma de nuestros montes y son unas veces suaves como el musgo que verdeguea en las peñas y otras robustas y enérgicas como los seculares robles de los sotos celtas constituyen el más envidiable tesoro de música popular. ${ }^{19}$

Non cabe dúbida que detrás desta raizame está a esencia do patriotismo, do celtismo, de construír país. E para amalo hai que coñecelo primeiramente. Nesa andaina, a música popular pode axudar formando parte da alma da escola mediante as súas diferentes versións e con formas representativas de diversos colectivos. A este respecto apunta:

\footnotetext{
Qué espectáculo más consolador el de una escuela gallega en la que se cantase nuestra música popular. Sería el homenaje más enternecedor y más justo debido a nuestra patria a quien hoy nos empeñamos en tener arrinconada como una vergonzosa cenicienta. Las notas saudosas del alalá, la alegría del canto de espadelada, la sonora rudeza del canto de arrieiro, la jovialidad y la algarearía del canto de ruada, el acompasado y animoso canto de arada, el retador canto de desafío, la ingeniosa regueifa, la muiñeira enxebre y tantos y tantos otros sonarían en nuestras escuelas como verdaderos cantos litúrgicos de la sagrada religión de la tierra madre. ${ }^{20}$
}

Así mesmo, Ben-Cho-Shey ve nestes cantos populares un instrumento útil para traballar co alumnado de educación especial, como puido comprobar nesa viaxe de estudos realizada a centros deste tipo en Francia e Bélxica, do que xa falamos, así como para a introdución do concepto de pacifismo no ámbito escolar. Achegan comprensión e amor entre os pobos e rexións con diferentes culturas. Dende unha postura cristiá, común por outra parte a todos os homes da xeración Nós, considera que o amor é moi necesario na ensinanza e na convivencia entre as nacións. Chega

\footnotetext{
${ }^{19}$ Ibidem, 7.

${ }^{20}$ Ibidem, 8
} 
a manifestar que dese coñecemento e comprensión duns pobos con outros, para o que nos pode servir perfectamente a música,

nace el amor; por el contrario puede decirse que se odia lo que se desconoce o no se comprende. Nuestra labor, que es una siembra educativa realizada con amor, debe tender a borrar los últimos rastros de odio que mantienen apartados a los pueblos y entenebrecen la vida, procurando por todos los medios a nuestro alcance que al conocerse íntimamente y descubrir las virtudes hoy ignoradas pueda llegar a ser una realidad el caritativo precepto de Cristo que ordena amarse los unos a los otros y que aún hoy suena a utopía pese a los veinte siglos de cristianismo.

A fonte dese caudal de recursos estaría no noso abundantísimo folclore. Nel temos cantares de todo tipo. A sabedoría popular fálanos de meteoroloxía, dos cantos mariñeiros que preparan para a faenas do mar, da emigración a Castela ou de despedida cando esta se produce a América, de descricións xeográficas, de alivio das penas, de naturismo referido a animais, de tenrura e emoción.

Agora ben, cabe puntualizar que non toda a música popular resulta apta para aplicar no ensino nin para transmitir valores patrióticos. Esta debe estar previamente ben seleccionada. Mais no caso de cumprir cos requisitos considerados idóneos polo mestre, nela, á parte de estaren presentes elementos expresivos e poéticos, encóntrase "la verdadera enjundia racial, es decir la esencia del patriotismo bien entendido. Busquemos, pues, el oro puro, y apartémonos del similor, de todo lo falso, de todo lo efectista".

Por último, como persoa comprometida que sempre tratou de ensinar a todos a coñecer, valorar e querer o noso país, despidámonos con aquelas palabras súas animándonos a que "hagamos pues nosotros el gran milagro de que gallegos y no gallegos conozcan a Galicia, y que más habíamos de pedir si ese gran milagro del que depende el resurgimiento de nuestra tierra se realizase cantando". ${ }^{21}$

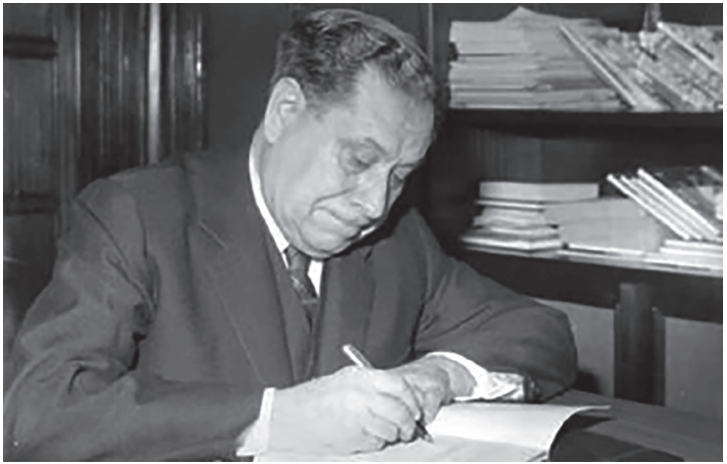

Ilustración 1. Ben-Cho-Shey asinándolle un exemplar do Catón Galego ao ministro de Educación (13-01- 1970).

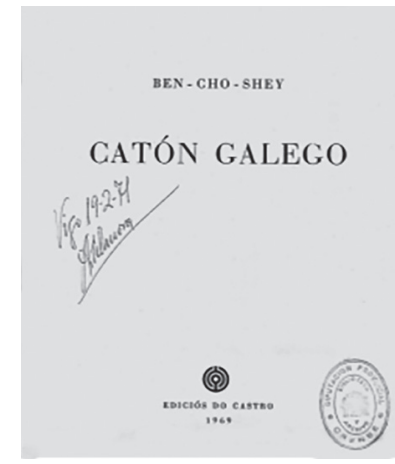

Ilustración 2. Portada do manual escolar Catón Galego.

${ }^{21}$ Ibídem, 13. 


\section{EL CANTO REGIONAL EN LAS ESCUELAS}

\section{Ponencia presentada por el Maestro Nacional José Ramón y Fernández Ojea al Congreso Pedagógico celebrado en La Coruña el año 1926.}

Afortunadamente para la Pedagogía contemporánea vivimos a una honesta distancia de aquellas escuelas antiguas tan herméticas y rígidas como faltas de espiritualidad en donde parecía rendirse culto al Silencio como supremo Dios y en las que se medía el valor pedagógico del maestro por su aire imponente y por su mayor capacidad para hacer contener la respiración de los alumnos.

Los diferentes tipos de escuela moderna -la escuela renovada, la escuela activa, la escuela del trabajo, etc.- han venido a revolucionar la enseñanza con sus procedimientos novísimos haciendo de la escuela un lugar grato en donde conviven amistosamente maestros y discípulos unidos en la redentora labor educativa que tiende a reivindicar para el niño sus derechos a la libertad de movimiento, a la libertad del trabajo, a la alegría, al juego y también al canto y a la danza.

El canto, especialmente, es entre todas las formas más o menos expresivas del arte la que mejor ha logrado aclimatarse en las escuelas, mucho mejor que el dibujo, que el modelado y que los trabajos manuales. Aún en aquellas escuelas en que más penoso se les hace el apartarse de la secular rutina se oye a veces cantar a los chicos. Cierto que en la mayoría de los casos el canto se reduce al monótono recitado en alta voz y con un mareado tonillo sacristanero de las tablas aritméticas y de ciertas oraciones de entrada y salida que están muy lejos de cumplir los fines que el canto debe llenar en la educación artística de los niños. Pero por algo se empieza.

Quizá fundado en esto ha podido decir el maestro Benedito: "En España, digámoslo con toda rudeza, apenas si se tiene concepto de lo que haya de ser el canto escolar. Ni los poetas ni los músicos han estudiado hondamente este aspecto, y es raro encontrar alguna que otra canción que llene plenamente estos fines. No quiero decir que no existan, pero si repetiré que es raro hallarlas." Y no es lo peor esta afirmación de persona tan autorizada como el Sr. Benedito; lo más grave es que es real y que todos los que tenemos un poco de sentimiento artístico hemos tenido ocasión de comprobarla una y cien veces.

Tal vez esto sea lo que me ha decidido a abordar el tema del "Canto regional en las escuelas" y del que habré de hablar con toda la prudencia que aconseja una de nuestras cantigas populares que dice así:

Antes que a falar te poñas

pensa no qu'has de decir

que moitos de non pensalo

chegarons arrepentir. 
Cosa que no quisiera que me ocurriese también a mi aunque no sea más que en gracia al gran interés que me ha despertado siempre esta cuestión de los cantos escolares y que a veces ha llegado a ser una verdadera preocupación.

Preocupación que surgió al conjuro de esos cánticos pedestres -a que antes hacía referencia- que llenan nuestras escuelas y que hacen tanto daño para el fin de la educación artística como pudieran hacerlo las coplas de los ciegos o los horrendos carteles que éstos emplean para ilustrarlas. Para mí, las tres cosas pertenecen a la misma categoría dentro de la esfera del arte.

Y no es que yo pretenda que nuestros escolares hayan de cantar a la perfección corales de Bach ni que los maestros estén obligados a ser unos músicos consumados, no. En arte una de las cualidades esenciales de toda obra bella es la sencillez y no por más complicado y amanerado resultaría más agradable el canto. Basta fijarse en lo monótonas y pesadas que resultan hoy esas obras orfeónicas tan en boga en la última mitad del pasado siglo. ¿Habrá alguien capaz de oir ejecutar una cualquiera de estas piezas musicales sin sentir el imperioso deseo de bostezar?

Pues otro tanto ocurre con los actuales cánticos escolares en los que la ramplonería corre pareja con el mal gusto. La mayoría de ellos son de una insoportable monotonía con la que han pretendido sus autores imitar la ansiada sencillez y delicadeza propia de las cosas dedicadas a la infancia y ninguno de ellos es capaz de despertar emoción en los niños que llegan a decirlos de una manera mecánica. Qué idea tan pobre se formaría de la música española el que hubiese de juzgarla a través de las canciones escolares que atrofian el sentimiento musical de los alumnos de nuestras escuelas. Desgraciadamente tampoco es mejor la parte seudo literaria que forma el cuerpo de las canciones escolares. Este es siempre un cuerpo hinchado, hueco, con apariencias y pretensiones de algo grande pero en realidad raquítico y de mal gusto. Parece como si se hubiesen puesto de acuerdo los peores potas con los músicos más faltos de inspiración para producir esos engendros hermanos gemelos del cuplé barato.

En Alemania, patria de excelsos músicos, se cuida mucho este aspecto de la educación y en la mayoría de las escuelas, niños y maestros ejecutan con verdadero amor delicadísimos lieders en los que a la fantasía de los mejores poetas se ha unido el genio de los grandes maestros de la música.

El lieder, sin embargo, es una obra musical sobremanera sencilla y saturada de poesía con un carácter marcadamente popular.

Mas no es cosa de que nos pasemos la vida perdiendo el tiempo en inútiles lamentaciones añorando lo que pueden tener de bueno otros pueblos sin preocuparnos de averiguar si nosotros poseemos algo mejor. Hora es ya de que investiguemos sin cesar lanzándonos a la búsqueda de lo que necesitamos con la seguridad de que hemos de encontrarlo a poco que revolvamos en la intrincada maraña de nuestro patrimonio artístico. 
Entonces experimentaremos la satisfacción de hallar lo que con tanta avidez perseguimos y nuestra alegría no tendrá límites al comprobar que es en nuestra propia casa y en el más apartado rincón, donde yace abandonado el objeto de nuestras preocupaciones.

Entonces podremos proclamar que también nosotros tenemos nuestro tesoro de música popular capaz de competir con su enorme valía con el de todos los pueblos europeos. Nuestras canciones populares que llenan con sus mágicas armonías todo el brumoso ambiente de la tierra gallega están saturadas del aroma de nuestros montes y son unas veces suaves como el musgo que verdeguea en las peñas y otras robustas y enérgicas como los seculares robles de los sotos celtas constituyen el más envidiable tesoro de música popular. El manantial, como veis, es purísimo y su abundancia solamente comparable a la fertilidad de nuestra tierra y a la fecundidad de nuestra raza.

\section{Cantares e mais cantares \\ cantares ch'hei de cantar; teño a hucha nova chea e un costal por desatar.}

Tal es la promesa que nos hace la pródiga musa de nuestro pueblo. No hace falta por lo tanto más que llegarse al florido huerto de nuestro ubérrimo folk-lore y saber escoger; aunque es tal la abundancia que escogiendo a ciegas había de hacerse buena cosecha.

Mas no sé porque sospecho que algunos espíritus apocados verán con recelo esta proposición mía y se preguntarán asustados: ¿es que pretende Vd. que cantemos alalás en nuestras escuelas? ¿Y por qué no? les pregunto yo a mi vez según el buen uso gallego. ¿Qué mal puede haber en ello?

A mi se me antoja que sólo beneficios se pueden obtener sustituyendo las actuales anodinas canciones escolares por los melodiosos cantares que son nuestro orgullo y creo firmemente que no sólo se deben cantar alalás en las escuelas gallegas sino toda la infinita y variadísima gama de cántigas populares que son la gala y el adorno de Galicia.

Qué espectáculo más consolador el de una escuela gallega en la que se cantase nuestra música popular. Sería el homenaje más enternecedor y más justo debido a nuestra patria a quien hoy nos empeñamos en tener arrinconada como una vergonzosa cenicienta. Las notas saudosas del alalá, la alegría del canto de espadelada, la sonora rudeza del canto de arrieiro, la jovialidad y la algarearía del canto de ruada, el acompasado y animoso canto de arada, el retador canto de desafío, la ingeniosa regueifa, la muiñeira enxebre y tantos y tantos otros sonarían en nuestras escuelas como verdaderos cantos litúrgicos de la sagrada religión de la tierra madre.

Y por si alguno quisiera ver en esta proposición mía -que ni siquiera tiene el mérito de la novedad- la exaltación de un arrebatado o la genialidad de un atrevido 
que sólo desea llamar la atención de los que caminan por las trilladas roderas de la rutina he de traer otra vez a colación la opinión autorizada del maestro Benedito.

"Entiendo - dice el competente músico- que lo más apropiado y eficaz para los comienzos del canto en la escuela es la 'canción natural', la que se canta por el pueblo en las distintas regiones españolas nacida directamente de la entraña misma de la naturaleza. Este es el venero rico, abundante, saludable, lleno de emoción y de vida, del que nos debemos surtir para depositar en el niño los principios embrionarios de un consciente, de un sano, de un recio patriotismo, y no esos mal llamados 'cantos patrióticos' que oímos en las escuelas, que no engendran el patriotismo, en modo alguno, sino un 'patriotismo' falso, de alharaca y de relumbrón, que hay que desechar valientemente por nocivo".

"En la canción regional - bien elegida desde luego- hay belleza natural, justeza en las imágenes, ingenuidad en la descripción, sabor, carácter, elementos expresivos y poéticos propios: en una palabra, en ellos encontramos la verdadera enjundia racial, es decir la esencia del patriotismo bien entendido. Busquemos, pues, el oro puro, y apartémonos del similor, de todo lo falso, de todo lo efectista".

Para el Sr. Benedito, según acabamos de ver, la enjundia racial y el verdadero patriotismo hemos de buscarlo en la canción regional. En esas canciones gallegas que acabo de enumerar y que son el más rico venero de inspiración artística y el más acabado modelo de educación musical para quien, como nuestros discípulos, han de ver transcurrir su vida en el ambiente rural en el que nacieron y con el que tan bien encuadran nuestros armonioso cantos.

Es un principio de buena didáctica el que el educador parta de lo conocido hacia lo desconocido; de este modo, nos dicen los pedagogos más en boga, es conveniente que se empiece a estudiar arrancando de la realidad en que vive el alumno, para ir poco a poco extendiendo la esfera de sus conocimientos hasta los más lejanos límites. Así se hace, por ejemplo, con los conocimientos geográficos y de igual forma se ha de proceder, en lo posible, en las demás disciplinas que forman el programa escolar. Y siendo así ¿por qué no adoptar el mismo procedimiento con el canto escolar?

Lo conocido, en este caso, es la canción popular, que tan familiar es para nuestros escolares, de la que nos valemos para conmemorar los más solemnes acontecimientos religiosos y profanos; la clásica canción de los mayos, con la que nuestros rapaces festejan la Primavera; la canción de ani novo, rebosante de ingenuidad y tradición, las cantigas de Natal, de un enternecedor primitivismo; el enxebre canto de pandeiro. Estos con los anteriormente citados y otros más que son gala de la poesía de nuestra tierra son los cantos más apropiados y que deben emplearse sin duda alguna en nuestras escuelas.

De esta forma lograremos que en los niños se vaya formando poco a poco la conciencia patriótica de que hoy carecen y al propio tiempo sabrán, cuando sean 
hombres, admirar todo el mérito de la música popular gallega a cuyo gran valor artístico se añadirá en cada uno de ellos el valor sentimental que para el adulto tiene todo lo que encierra un recuerdo de la infancia.

Y así cuando en los amargos días de la emigración, allá en la ausencia a que obliga la lucha por la vida, acaricien sus oídos las melosas notas de alguna de nuestras dulces cántigas, mezclado con los recuerdos del hogar y de la madre vendrá a su memoria también la lembranza de la escuelita en que vio discurrir su niñez alegremente y en la que también se cantaban aquellos cantos que ahora en tal lugar y momento vienen a mitigar sus dolores y a fortalecerle para triunfar en la penosa tarea del vivir cotidiano.

Es evidente que del conocimiento y de la comprensión nace el amor; por el contrario puede decirse que se odia lo que se desconoce o no se comprende. Nuestra labor, que es una siembra educativa realizada con amor, debe tender a borrar los últimos rastros de odio que mantienen apartados a los pueblos y entenebrecen la vida, procurando por todos los medios a nuestro alcance que al conocerse íntimamente y descubrir las virtudes hoy ignoradas pueda llegar a ser una realidad el caritativo precepto de Cristo que ordena amarse los unos a los otros y que aún hoy suena a utopía pese a los veinte siglos de cristianismo.

Hagamos pues nosotros el gran milagro de que gallegos y no gallegos conozcan a Galicia, y qué más habíamos de pedir si ese gran milagro del que depende el resurgimiento de nuestra tierra se realizase cantando.

A modo de complemento del anterior trabajo háseme ocurrido el hacer una pequeña colección de cantares populares que pudieran emplearse en nuestras escuelas. Es un modesto ramillete recogido en el frondoso jardín de nuestro abundantísimo folk-lore. Pertenecen en su mayoría a esta provincia de la Coruña y abarcan una porción de cuestiones heterogéneas.

Empezaré por los que pudiéramos llamar de tipo meteorológico y con los cuales se hace referencia bien a algún astro bien a cualquier fenómeno de aquella especie. De los primeros es la siguiente copla:
Alomeame, alomeame
estreliña da Fortuna
alomeame, alomeame
mentras que non ven a Luna.

Entre los segundos encontramos este que muestra lo poco que preocupa la lluvia a quien cuenta con un cobijo que lo ponga a buen recaudo del agua.
Si chove, deixa chover;
si orvalla, deixa orvallar
qu'eu ben sei d'un abriguiño
onde m 'hei d'ir a abrigar. 
El viento Norte, que despeja nuestro cielo es a la vez excelente motor de las lanchas de pesca, por eso nuestros marineros le saludan con alegría y se preparan para las rudas faenas del mar exclamando:

$$
\begin{aligned}
& \text { Vente ventiño do Norte, } \\
& \text { vente ventiño norteiro, } \\
& \text { vente ventiño do Norte } \\
& \text { arriba meu compañeiro. }
\end{aligned}
$$

Veamos ahora estos cantares naturalistas en que la sabiduría popular nos habla de animales, de plantas y de frutas:

\section{Catro aves escollidas} son as que pasan o mar: o cuco, e a andoriña, a rula e o paspayás.

El otro que dice:

$$
\begin{aligned}
& \text { Que demo de merlo mouro } \\
& \text { donde foi poner o niño } \\
& \text { cuberto con unhas ponlas } \\
& \text { no medio d'un carballiño. }
\end{aligned}
$$

Donde se ve que, por mucha sagacidad que los pájaros tengan para ocultar su nido, siempre será poca para librarse de la persecución del hombre.

También pertenece a este grupo el conocidísimo cantar que dice:

$$
\begin{aligned}
& \text { Xa fun a Marin, } \\
& \text { xa pasei o mar, } \\
& \text { xa comin laranxas } \\
& \text { do teu laranxal. }
\end{aligned}
$$

Y este otro donde la lozanía de un repollo, o quizá la juventud de la hortelana, a quien se nombra en sentido figurado, provoca la admiración y el deseo del labriego que canta:

$$
\begin{aligned}
& \text { Quen che me dera repolo } \\
& \text { repoliño repolado } \\
& \text { quen che me dera repolo } \\
& \text { na miña horta plantado. }
\end{aligned}
$$

Más no siempre es alegre o irónico nuestro cantar; también hay quien canta para aliviar sus penas, como en la copla que sigue: 
Eu non canto por cantar nin por ganas que lle teña que canto por aliviar do meu corazón a pena.

O para no dar lugar a la murmuración, como en este otro:

O meu cantar xa non viste

Canto para que non digan:

Alegre? por que estás triste?

La emigración anual a Castilla para realizar las faenas de la siega, ha dado lugar a numerosos cantares, no siempre favorables para esta región de donde regresan los segadores agotados por un trabajo que quizá fuera de más rendimiento si se llevase a cabo en el propio solar. Así nos lo asegura la siguiente filosófica copla:

A Castilla van os homes

a Castilla por ganar

Castilla queda na terra

para quen quer traballar.

He aquí un cantar en donde a más de los días de la semana se dicen verdades de a puño:
Hoxe é luns, mañan é martes, cuarta feira logo ven, de mañan en oito días éche a semana que ven.

Si siempre es triste una despedida, mucho más ha de serlo para quien como los gallegos llevamos tan dentro del alma el amor a la tierra personificada en el paisaje.
Adiós ríos, adiós fontes adiós regatos pequenos, adiós vista dos meus ollos non sei cando nos veremos.
Adios que che m`embarco d'esta terra para a outra co a auga dos meus ollos lavarás a miña roupa.

Son abundantísimos en nuestro folklore los cantares geográficos en los cuales con una sencillez maravillosa y una justeza grande se nos da la visión de una comarca más o menos extensa, como en una película cinematográfica. Sirven de ejemplo los siguientes: 
Vexo o Faro, vexo o Faro

e tamén vexo o Farelo,

tamén vexo Pico-sagro

e ademais o Bodelo.

Todos estos montes se divisan desde Arzúa.

Para Sada vai o mar

para Betanzos o río,

para pasar o Fontán

hay que atracar un navío.

¿Quién con menos palabras nos retrata mejor el bellísimo rincón de las Mariñas como lo hace este cantar?

Este otro, en cambio, nos recuerda el paso rápido del automóvil al cruzar la carretera de Santiago a La Coruña en donde están todos los pueblos que menciona:
Palavea y-o Portazgo
Pedralonga y-o Areal
vivan con Rio de Quintas
o pe do camino real.

También la costa brava del Ortegal está admirablemente vista en este cantar de despedida de aquel hermoso país:

Adiós Estaca de Bares,

Aguilloes de Cariño

un pouquiño mais adiante

o San Andrés de Teixido.

El carácter acogedor hospitalario de la ciudad del Lérez está perfectamente reflejado en este otro:

Pontevedra é boa vila

dá de beber a quen pasa

na fonte da Ferrería

San Bartolomé e a Praza.

El conocidísimo cantar:
Vexo Vigo, vexo Cangas, tamén vexo Redondela
vexo a Ponte de Sampayo
camiño da miña terra.

Sintetiza maravillosamente el espléndido panorama de la ría de Vigo. Y otro tanto puede decirse de este último en el que también se describe el valle de Verín: 


\section{Verín estavos no baixo, \\ Monterrey está no alto, \\ Nosa Señora da Estrela \\ está n-un campiño raso.}

Y por último, como mejor remate de esta ya larga enumeración de cantares gallegos, vayan estos dos tan pequeños en la forma como grandes en el fondo que encierran cada uno todo un poema de ternura y emoción y que hablan al alma del incomparable amor de una madre capaz de suplir con sus caricias la falta de alimento. Difícil es encontrar nada que llegue con tanta fuerza emotiva a las fibras más hondas del sentimiento como estas dos cantigas dignas de ser perpetuadas con letras de oro. Juzgad sino:

Miña nai, miña naiciña, como a miña nai ningunha que me quenta a cariña co calorciño da súa.

Miña nai como é probe e non ten pan que me dar enchem'a cara de bicos e despois rompe a chorar.
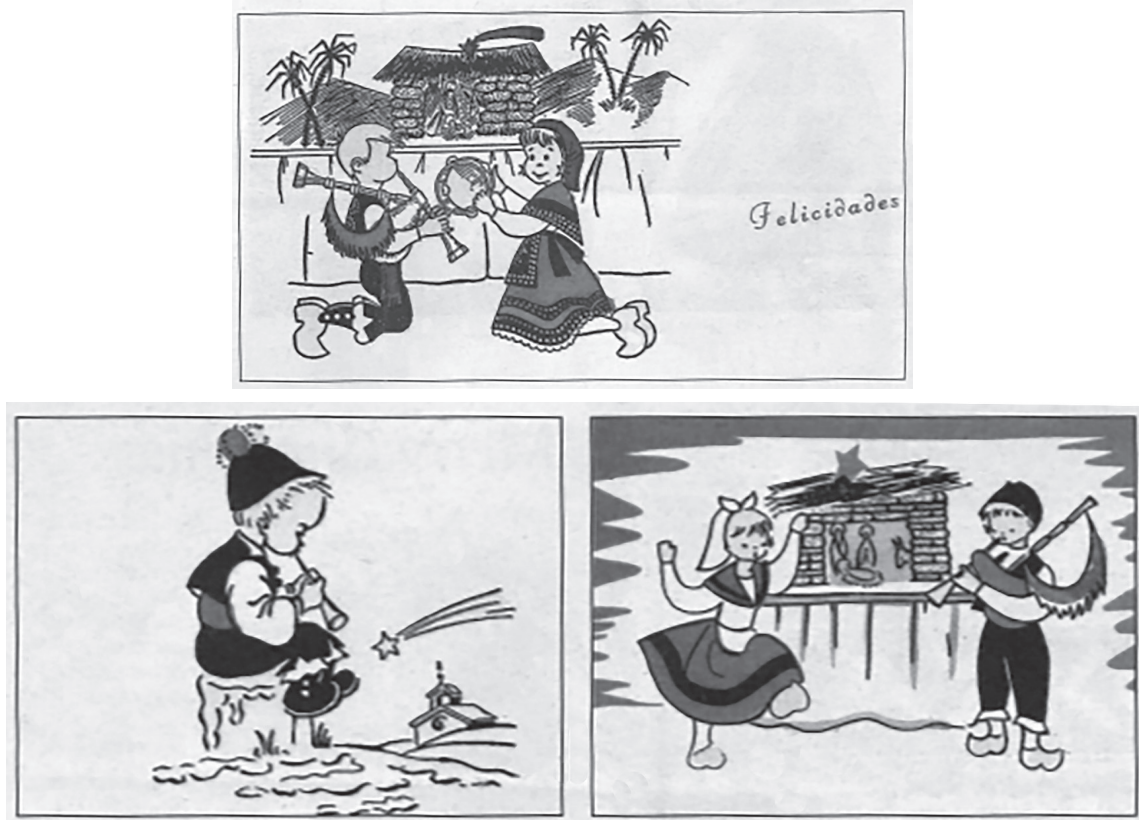

Ilustración 3. Tarxetas de Nadal coleccionadas por Ben-Cho-Shey con nenos e nenas bailando e tocando instrumentos rexionais. 